\title{
Video Article \\ Microwave Assisted Rapid Diagnosis of Plant Virus Diseases by Transmission Electron Microscopy
}

\author{
Bernd Zechmann ${ }^{1,2}$, Gerhard Graggaber ${ }^{1}$, Günther Zellnig ${ }^{1}$ \\ ${ }^{1}$ Institute of Plant Sciences, University of Graz \\ ${ }^{2}$ Institute for Electron Microscopy and Fine Structure Research, Graz University of Technology \\ Correspondence to: Bernd Zechmann at bernd.zechmann@uni-graz.at
}

URL: https://www.jove.com/video/2950

DOI: doi:10.3791/2950

Keywords: Immunology, Issue 56, diagnostics, electron microscopy, microwave, Nicotiana, negative staining, phytopathology, TMV, ultrastructure

Date Published: $10 / 14 / 2011$

Citation: Zechmann, B., Graggaber, G., Zellnig, G. Microwave Assisted Rapid Diagnosis of Plant Virus Diseases by Transmission Electron Microscopy. J. Vis. Exp. (56), e2950, doi:10.3791/2950 (2011).

\section{Abstract}

Investigations of ultrastructural changes induced by viruses are often necessary to clearly identify viral diseases in plants. With conventional sample preparation for transmission electron microscopy (TEM) such investigations can take several days ${ }^{1,2}$ and are therefore not suited for a rapid diagnosis of plant virus diseases. Microwave fixation can be used to drastically reduce sample preparation time for TEM investigations with similar ultrastructural results as observed after conventionally sample preparation ${ }^{3-5}$. Many different custom made microwave devices are currently available which can be used for the successful fixation and embedding of biological samples for TEM investigations ${ }^{5-8}$. In this study we demonstrate on Tobacco Mosaic Virus (TMV) infected Nicotiana tabacum plants that it is possible to diagnose ultrastructural alterations in leaves in about half a day by using microwave assisted sample preparation for TEM. We have chosen to perform this study with a commercially available microwave device as it performs sample preparation almost fully automatically ${ }^{5}$ in contrast to the other available devices where many steps still have to be performed manually ${ }^{6-8}$ and are therefore more time and labor consuming. As sample preparation is performed fully automatically negative staining of viral particles in the sap of the remaining TMV-infected leaves and the following examination of ultrastructure and size can be performed during fixation and embedding.

\section{Video Link}

The video component of this article can be found at https://www.jove.com/video/2950/

\section{Protocol}

\section{Microwave assisted sample preparation}

1. Before the start of sample preparation one needs to program the automatic microwave tissue processor for electron microscopy (Leica EM AMW; Leica Microsystems, Vienna, Austria) with the following protocols (Table 1) for microwave assisted sample preparation for TEM: 


\begin{tabular}{|c|c|c|c|c|c|c|}
\hline $\begin{array}{l}\text { Vial } \\
\text { nr. }\end{array}$ & Step & Reagent & Duration & $\begin{array}{l}\text { Max. temp. } \\
\left({ }^{\circ} \mathrm{C}\right)\end{array}$ & $\begin{array}{l}\text { Microwave } \\
\text { mode }\end{array}$ & $\begin{array}{l}\text { Max. } \\
\text { power (W) }\end{array}$ \\
\hline \multicolumn{7}{|c|}{ Protocol for fixation, dehydration and infiltration } \\
\hline \multirow[t]{4}{*}{1} & 1 & $3 \%$ Glutaraldehyde in $60 \mathrm{~mm}$ phosphate buffer & $2 \mathrm{~min}$ & 37 & Continuous & 15 \\
\hline & 2 & & $2 \min$ & 20 & Continuous & 0 \\
\hline & 3 & & $2 \min$ & 37 & Continuous & 15 \\
\hline & 4 & & $2 \mathrm{~min}$ & 20 & Continuous & 0 \\
\hline 2 & 5 & $60 \mathrm{~mm}$ Phosphate buffer & $1 \min$ & 37 & Slope & 20 \\
\hline 3 & 6 & $60 \mathrm{mM}$ Phosphate buffer & $1 \mathrm{~min}$ & 37 & Pulse & 15 \\
\hline 4 & 7 & $60 \mathrm{mM}$ Phosphate buffer & $1 \mathrm{~min}$ & 37 & Slope & 20 \\
\hline 5 & 8 & $1 \%$ Osmium tetroxide in $60 \mathrm{~mm}$ phosphate buffer & $12 \min$ & 37 & Continuous & 15 \\
\hline 6 & 9 & $60 \mathrm{mM}$ Phosphate buffer & $1 \mathrm{~min}$ & 37 & Continuous & 15 \\
\hline 7 & 10 & $60 \mathrm{~mm}$ Phosphate buffer & $1 \mathrm{~min}$ & 37 & Continuous & 15 \\
\hline 8 & 11 & $60 \mathrm{~mm}$ Phosphate buffer & $1 \mathrm{~min}$ & 37 & Continuous & 15 \\
\hline 9 & 12 & $50 \%$ Acetone & $1 \min$ & 37 & Slope & 20 \\
\hline 10 & 13 & $70 \%$ Acetone & $1 \mathrm{~min}$ & 37 & Slope & 20 \\
\hline 11 & 14 & $90 \%$ Acetone & $1 \mathrm{~min}$ & 37 & Slope & 20 \\
\hline 12 & 15 & $100 \%$ Acetone & $2 \min$ & 37 & Slope & 20 \\
\hline 13 & 16 & $100 \%$ Acetone & $2 \mathrm{~min}$ & 37 & Slope & 20 \\
\hline 14 & 17 & Epow-resin: $100 \%$ Aceton $=1: 3$ & $3 \min$ & 37 & Continuous & 10 \\
\hline 15 & 18 & Epoxy-resin: $100 \%$ Aceton $=1: 1$ & $3 \mathrm{~min}$ & 40 & Continuous & 10 \\
\hline 16 & 19 & Epoxy-resin: $100 \%$ Aceton $=3: 1$ & $3 \min$ & 45 & Continuous & 10 \\
\hline 17 & 20 & $100 \%$ Epoxy resin & $3 \mathrm{~min}$ & 50 & Continuous & 12 \\
\hline 18 & 21 & $100 \%$ Epoxy resin & $3 \min$ & 50 & Continuous & 12 \\
\hline 19 & 22 & $100 \%$ Epoxy resin & $3 \min$ & 50 & Continuous & 12 \\
\hline \multicolumn{7}{|c|}{ Protocol for polymerization } \\
\hline \multirow[t]{4}{*}{1} & 1 & $100 \%$ Epoxy resin & $5 \mathrm{~min}$ & 65 & Slope & 30 \\
\hline & 2 & & $5 \mathrm{~min}$ & 78 & Slope & 30 \\
\hline & 3 & & $15 \mathrm{~min}$ & 90 & Slope & 30 \\
\hline & 4 & & $60 \mathrm{~min}$ & 90 & Continuous & 30 \\
\hline & & Total time: & $136 \mathrm{~min}$ & & & \\
\hline
\end{tabular}

Table 1. Protocol for sample preparation using microwave irradiation. The different columns show (from left to right):

1. Vial number (Vial $n r$.) represents the order in which the vial is loaded into the carousel of the processor.

2. Step of the actual process.

3. Reagents in the vials.

4. Duration of the actual step.

5. Maximum temperature which is reached in the vial before the microwave irradiation is turned off.

6. Microwave irradiation setting: Continuous $=$ rapid temperature increase, holding the set temperature; Slope=gentle temperature increase, final temperature reached at the end; Pulsed=Rapid temperature increase, power turned off until the temperature dropped $5^{\circ} \mathrm{C}$, power resumed to reach temperature.

7. Maximum power of the microwave irradiation.

2. Freshly prepare the solutions for the different steps described in the sample preparation protocol (for Agar 100 epoxy resin see 1.7), fill them into the designated vials according to the programmed protocol (Table 1), load the vials on the carousel, then insert the carousel into the microwave tissue processor, and finally load the first vial into the mono-mode chamber. 
3. Cut out small sections of leaves $\left(1 \mathrm{~mm}^{2}\right)$ from Nicotiana tabacum infected with Tobacco Mosaic Virus (TMV) with a razor blade on a modeling wax plate in a drop of 3\% glutaraldehyde (Agar Scientific Ltd., Stansted, England) in 60mM Sørensen phosphate buffer (pH 7.2) at room temperature.

4. Transfer the sections with fine tweezers immediately into the designated baskets with a mesh width of approximately $200 \mu m$. Stack the baskets on top of each other and insert them into the mono-mode chamber. Care must be taken that the samples are constantly covered with fixative solution during loading and stacking of the baskets so that they do not dry out.

5. Start the previously programmed microwave assisted sample preparation protocol for fixation, dehydration and infiltration.

6. While sample preparation is performed automatically by the microwave tissue processor continue with negative staining with the remaining plant material as described in section 3 (negative staining).

7. Freshly prepare Agar 100 epoxy resin by mixing the following components as described: fill $24 \mathrm{~g}$ Agar $100,16 \mathrm{~g}$ dodecenyl succinic anhydride, and $10 \mathrm{~g}$ methyl nadic anhydride (for all components see Agar Scientific Ltd., Stansted, England) in a plastic cup, heat it to $40^{\circ} \mathrm{C}$ and mix it well. Add $1.2 \mathrm{~g}$ of benzyl dimethylamine and mix thoroughly. Fill Agar 100 epoxy resin into the designated polymerization forms just before the sample preparation protocol comes to an end (e.g. during step 22 in table 1).

8. After the protocol is finished (after step 22 in table 1) release the stacked baskets containing the infiltrated samples from the mono-mode chamber into the last vial of the carousel. Remove the carousel from the microwave device, unstack the baskets and load them by using fine tweezers into the designated polymerization forms. Care must be taken that the samples are always covered with Agar 100 epoxy resin during unstacking and loading so that they do not dry out

9. Stack the polymerization forms on top of each other. Care must be taken that the samples are always covered with Agar 100 epoxy resin during stacking and loading so that they do not dry out.

10. Remove previously used vials from the carousel of the microwave tissue processor, load it with the stacked baskets and insert the carousel into the microwave tissue processor.

11. Start the previously programmed polymerization protocol (table 1).

12. While polymerization is carried out automatically by the microwave tissue processor, examine negatively stained grids with a transmission electron microscope [e.g. Philips CM10 TEM, FEl (formerly Philips), Eindhoven, The Netherlands] and perform image analysis as described in section 3 and 4 (negative staining and image analysis).

13. After the protocol is finished remove the polymerization forms from the mono-mode chamber, unstack the polymerization forms and remove the polymerized blocks containing the samples. They are now ready to be sectioned with a microtome.

\section{Trimming and sectioning}

1. Insert one or more blocks into separate sample holders for ultrathin sectioning with the sample on top sticking about $1 \mathrm{~cm}$ out of the holder.

2. Trim the block with a specimen trimmer for TEM (e.g. Leica Reichert Ultratrim; Leica Microsystems) so that a block face of max. $1 \mathrm{~mm}$ in length and $200 \mu \mathrm{m}$ in width which contains as much leaf material as possible is achieved (block face size might need to be adjusted to the size of the diamond knife).

3. Section the block with an ultramicrotome (e.g. Reichert Leica Ultracut S; Leica Microsystems) by using a diamond knife at a knife angle of $45^{\circ}$ (e.g. Diatome Ultra 45, Gröpl, Tulln, Austria). Section thickness should be adjusted to about 70 to $90 \mathrm{~nm}$ and the cutting speed should be around $1 \mathrm{~mm} / \mathrm{s}$. Pick up multiple sections with a formvar (Agar Scientific Ltd.) coated copper or nickel 200 square mesh grid.

4. Post-stain the sections on the grid with lead citrate (Agar Scientific Ltd.; $1.1 \mathrm{~g}$ lead citrate dissolved in $42 \mathrm{ml}$ double distilled water and $8 \mathrm{ml} 1 \mathrm{~N}$ $\mathrm{NaOH})$ for 5 minutes in a petri dish partly filled with $\mathrm{NaOH}$ to create a $\mathrm{CO}_{2}$-free environment and for 15 minutes with $1 \%$ uranyl acetate $($ Agar Scientific Ltd.) dissolved in distilled water at room temperature. Wash the grids with distilled water for 1 minute in between each post-staining step. Air dry the grids in a grid box.

5. Examine sections with a transmission electron microscope (e.g. Philips CM10 TEM, FEI, Eindhoven, The Netherlands).

\section{Negative staining}

1. Harvest about $100 \mathrm{mg}$ of TMV-infected leaf material and prepare crude sap by homogenizing the material for 2 minutes with a razor blade on a microscope slide in $100 \mu \mathrm{l}$ of $60 \mathrm{mM}$ Søfrensen phosphate buffer $(\mathrm{pH} 7.2)$.

2. Transfer $20 \mu \mathrm{l}$ of the resulting homogenate onto the first well of a teflon coated microscope slide with 4 or more wells (alternatively it is also possible to transfer the homogenate on a piece of parafilm).

3. Place a formvar coated grid on top of the homogenate with the formvar (Agar Scientific Ltd.) coated side facing towards the drop and incubate it for 5 minutes.

4. Wash the grid 2 times for 2 minutes each by placing the grid on top of two drops of $200 \mu \mathrm{l} 60 \mathrm{mM}$ Sørensen phosphate buffer (pH 7.2).

5. Incubate the grid for 1 minute with a freshly prepared $2 \%$ phosphotungstic acid (Agar Scientific Ltd.) solution in 60mM Sørensen phosphate buffer ( $\mathrm{pH}$ 6.5).

6. Remove the grid and allow it to air dry in a grid box.

7. Examine the grid with a transmission electron microscope (e.g. Philips CM10 TEM; FEI, Eindhoven, The Netherlands). Take at least 10 images of randomly chosen negatively stained virions (at least 10 or more virions should be visible on each image) with the transmission electron microscope at a primary magnification of $21000 \mathrm{X}$ or higher. Care must be taken that all images have the same magnification.

\section{Image analysis}

1. Measure the length and width of at least 100 randomly chosen single virus particles on the micrographs taken from the negatively stained samples by using any image analysis computer software [e.g. Cell D (Olympus, Life and Material Science Europe GmbH, Hamburg, Germany) with the particle analysis tool or Optimas 6.5.1- (Media Cybernetics Inc., Bethesda, Maryland, USA)].

2. Calculate means and standard deviations in order to achieve an average length and width of the virus particles visualized by negative staining methods and TEM. 
3. Compare length and ultrastructural features (obtained in 2.5) with sizes of viruses and ultrastructural alterations induced by virus diseases known in the literature in order to clearly identify the virus diseases.

\section{Representative results:}

After microwave assisted sample preparation typical TMV-induced ultrastructural alterations such as large areas containing virions aligned in parallel form could be observed with the transmission electron microscope in the cytosol of infected Nicotiana tabacum cells (Fig 1A).

Additionally, in the crude sap of TMV-infected leaves TMV particles could be observed as flexuous, rod-shaped structures after negative staining (Fig 1B). Image analysis of 100 virus particles revealed an average size for TMV of $280 \mathrm{~nm}$ in length and $17 \mathrm{~nm}$ in width (Fig 2). The ultrastructure in TMV-infected cells and the size of virions observed in this study were found to be in accordance with TMV-induced ultrastructural properties in tobacco and the size range of TMV particles previously reported in the literature ${ }^{9-15}$.

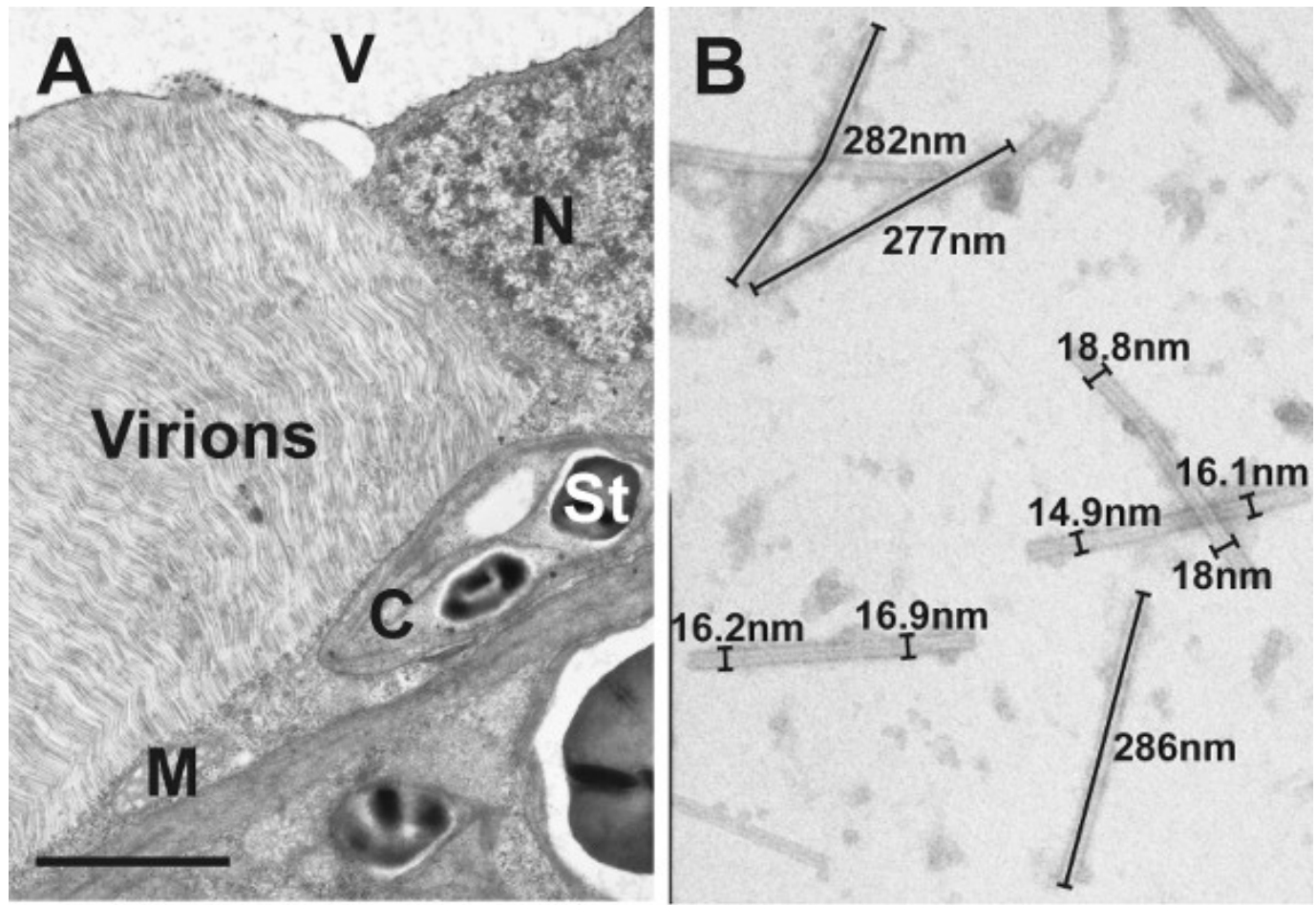

Figure 1. Transmission electron micrographs of TMV-infected leaf cells and virions. A) Image shows the ultrastructure of TMV-infected mesophyll leaf cells of Nicotiana tabacum after microwave assisted plant sample preparation. Note the large area of parallel aligned virions which accumulated in the cytosol. $C=$ chloroplast with starch (St), $M=$ mitochondrion, $N=$ nucleus, $V=$ vacuole, Bar=2 $\mu m$. B) Image shows virions which were detected by negative staining in the sap of infected leaves. 

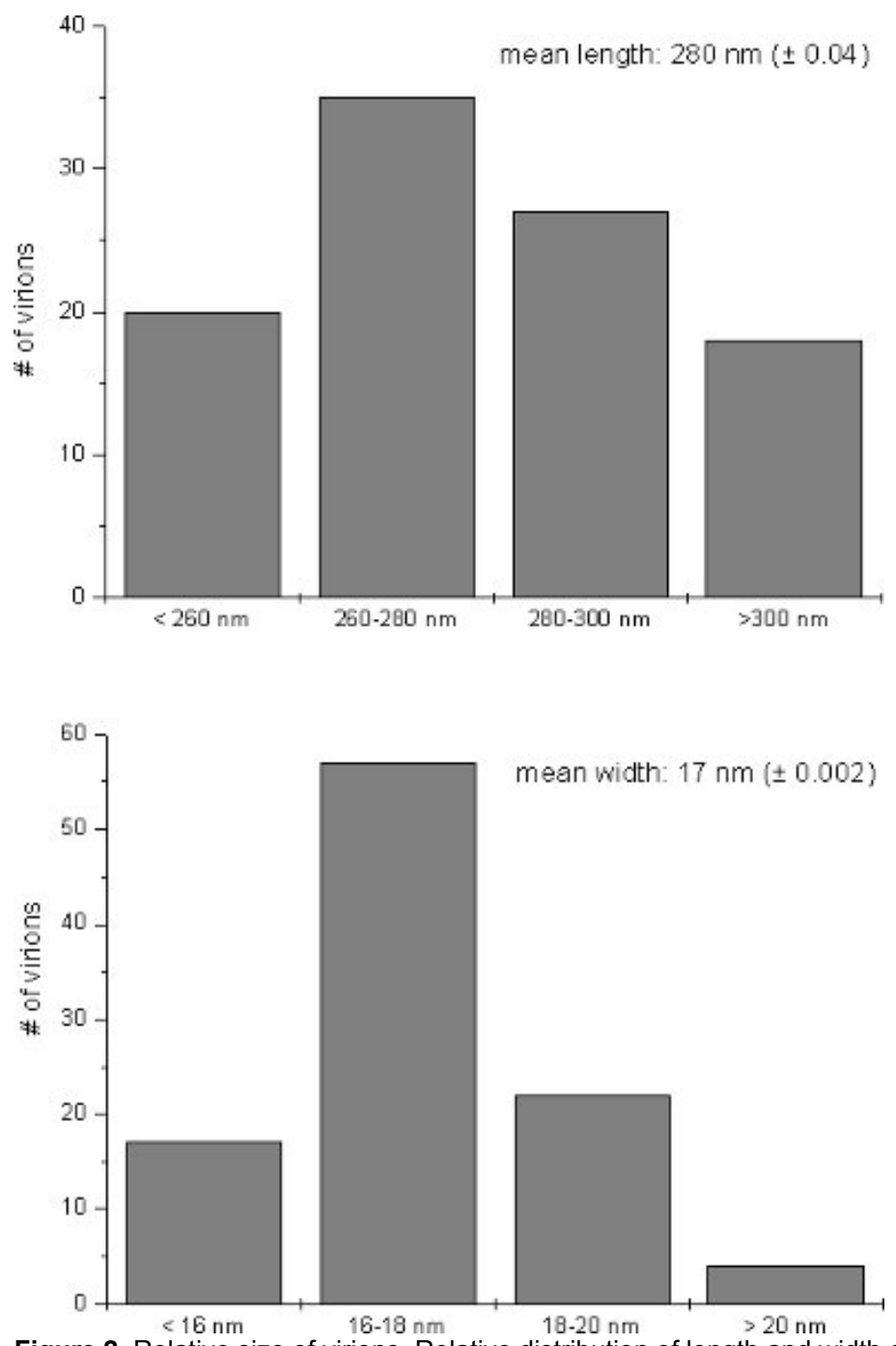

Figure 2. Relative size of virions. Relative distribution of length and width of TMV-particles after negative staining the sap of infected leaves as they appeared in the electron microscope. Mean values (mean length/width \pm standard deviation) were calculated from 100 virions.

\section{Discussion}

Microwave assisted plant sample preparation for TEM has been proven to supply fast and reliable ultrastructural data within a few hours ${ }^{3,4,16}$. The fine structural preservation of organelles and membranes achieved with the method used in this study was similar to conventional and cryofixed samples ${ }^{5,15}$ with the advantage of a massive reduction in sample fixation and embedding time from 3 days or longer to about 2 hours. This represents the fastest sample preparation protocol for TEM currently available in the literature. The method described in this study combined microwave assisted plant sample preparation for TEM with negative staining methods which allowed a clear and rapid identification of TMV-induced ultrastructural alterations and the viral agent itself. TMV induced ultrastructural alterations could be investigated after trimming, sectioning and post-staining within about 4 hours after the beginning of fixation in the transmission electron microscope. Using the fully automatically specimen preparation mode freed the researcher to conduct negative staining in the interim in order to determine the size and width of the viral agent. Thus, we can conclude that this method allows a clear and rapid diagnosis of plant virus diseases in about half a day which is of great importance for future use in agriculture and scientific experiments in plant phytopathology. As this method could also be used for the rapid diagnosis of animal and human diseases it has a large potential for future application in medical and veterinary pathology.

\section{Disclosures}

No conflicts of interest declared.

\section{Acknowledgements}

This work was supported by the Austrian Science Fund (FWF, P20619 and P22988 to B.Z.). 


\section{References}

1. Bozzola, J.J. \& Russell, D. Electron Microscopy. (Jones and Barlett Publishers, Boston, 1999).

2. Kuo, J. Processing plant tissues for ultrastructural study. Methods in Molecular Biology, Electron Microscopy, Methods and Protocols (J. Kuo, eds.), 369, Humana Press, 47-65 (2007).

3. Schroeder, J.A., Gelderblom, H.R., Hauroeder, B., Schmetz, C., Milios, J., \& Hofstaedter, F. Microwave-assisted tissue processing for sameday EM-diagnosis of potential bioterrorism and clinical samples. Micron. 37, 577-590 (2006).

4. Webster, P. Microwave-assisted processing and embedding for transmission electron microscopy. Methods in Molecular Biology, Electron Microscopy, Methods and Protocols (J. Kuo, eds.), 369, Humana Press, 47-65 (2007).

5. Zechmann, B. \& Zellnig, G. Microwave assisted rapid plant sample preparation for transmission electron microscopy. J. Microsc. 233 258-268 (2009).

6. Lería, F., Marco, R., \& Medina, F.J. Structural and antigenic preservation of plant samples by microwave-enhanced fixation, using dedicated hardware, minimizing heat-related effects. Micr. Res. Techniq. 65, 86-100 (2004).

7. Giberson, R.T., Austin, R.L., Charlesworth, J., Adamson, G., \& Herrera, G.A. Microwave and digital imaging technology reduce turnaround times for diagnostic electron microscopy. Ultrastruct. Pathol. 27, 187-196 (2003).

8. Cavusoglu, I., Minbay, F.Z., Temel, S.G., \& Noyan S. Rapid polymerisation with microwave irradiation for transmission electron microscopy. Eur. J. Morph. 39, 313-317 (2001).

9. Ermolina, I., Morgana, H., Greena, N.G., Milnerb, J.J., \& Feldmanc, Y. Dielectric spectroscopy of tobacco mosaic virus. Biochim. Biophys. Acta. 1622, 57-63 (2003).

10. Maeda, H. An atomic force microscopy study for the assembly structures of tobacco mosaic virus and their size evaluation. Langmuir. 13, 4150-4161 (1997).

11. Milne, R.G. Multiplication of tobacco mosaic virus in tobacco leaf palisade cells. Virology. 28, 527-532 (1966).

12. Reunov, A.V., Gnutova, I.V., \& Lapshina, L.A. Effect of tobacco mosaic virus strains on the ultrastructure of tobacco leaf parenchymal cells. Biol. Bull. 33, 409-415 (2006).

13. Sachse, C., Chen, J.Z., Coureux, P.D., Stroupe, M.E., Fändrich, M., \& Grigorieff, N. High-resolution electron microscopy of helical specimens: a fresh look at tobacco mosaic virus. J. Mol. Biol. 371, 812-835 (2007).

14. Smith, M.L., Lindbo, J.A., Dillard-Telm, S., Brosio, P.M., Lasnik, A.B., McCormick, A.A., Nguyen, L.V., \& Palmer, K.E. Modified tobacco mosaic virus particles as scaffolds for display of protein antigens for vaccine applications. Virology. 348, 475-488 (2006).

15. Zechmann B. \& Zellnig G. Rapid TEM diagnosis of plant virus diseases. J. Virol. Meth. 162, 163-169 (2009).

16. Giberson, R.T. \& Demaree Jr., R.S. Microwave processing techniques for electron microscopy: a four-hour protocol. Meth. Molec. Biol. 117, $145-158$ (1999). 